\title{
The Application of Error Analysis in Writing Based on Automatic Scoring System
}

\author{
Chunfang $\mathrm{Li}^{1, \mathrm{a}}$ \\ ${ }^{1}$ Foreign Department, Bohai University, Jinzhou City, Liaoning Province, China \\ a1635119146@qq.com
}

\begin{abstract}
Students should master the basic knowledge of the primary skill of writing, so as to form a comprehensive application of English knowledge and ability. English writing plays a vital role as the output skill among the four basic skills. However, numerous studies have shown that most junior high school students cannot easily complete an English composition without any problems. For the sake of improving students' English writing ability, it is quite necessary to analyze mistakes in compositions and find out effective teaching methods. Error analysis is of great guiding significance to students' English writing. However, facing with the large number of students in one class, this task seems to be heavy and inefficient for teachers. Artificial intelligence technology can be widely used in the process of English teaching and students' learning. One of the applications of artificial intelligence technology related to students' English writing correction is automatic scoring system. By using the automatic scoring system, the workload of teachers can be effectively reduced so that students can get amendments to their own composition. According to this amendment, students can modify their English composition appropriately so as to improve their English writing level.
\end{abstract}

Keywords: automatic scoring system, error analysis, English writing

\section{INTRODUCTION}

From the practice of English teaching, we can draw the indispensable position of English writing in students' English learning (Pellegrino \& Hilton, 2013). The purpose of this paper is to take advantage of Error Analysis to analyze the errors students made in their English writing based on the automatic scoring system, so as to find out the mistakes that often occur in English writing, and to provide the direction for the teaching of English writing.

\subsection{Research Background}

As a teacher, correcting students' English compositions in daily teaching is a headache, because of facing with so many students in one class, the workload of English teachers is undoubtedly huge and inefficient. Therefore, it is impossible to analyze the errors in students' English compositions and give some suggestions for reference to promote the improvement of students' English writing proficiency in a limited time. However, with the swift development of science and technology, under the background of big data, it is possible for a large number of tools and auxiliary systems to be widely used in English teaching. E-rater was first applied to the test of GMAT (The Graduate Management Admission Test) in foreign countries. In China, the widely used automatic English composition evaluation system is "Ju $\mathrm{Ku}$ " network and so on (Chukharew-Dianainen \& Saricaoglu, 2016). Yin, Jia and Lin (2017) indicate that there is a high positive correlation between the automatic scoring system and the manual correction of the compositions. The Error Analysis in this paper will use the information obtained from the correction of $\mathrm{Ju} \mathrm{Ku}$ to see its influence on the English writing level for junior middle school students.

\subsection{The Purpose and Significance of the Study}

In practical writing teaching, it is common that Junior middle school students have different language errors in their compositions. Therefore, it is necessary to make a systematic analysis of the mistakes they make in compositions. Through analyzing students' errors in their compositions, it is helpful for English teachers to take corresponding teaching methods to reduce or even put an end to the recurrence of this type of errors. Furthermore, when analyzing those errors, not only teachers, but also students will have an accurate location for errors. They would realize that mistakes actually play an active role in promoting students' English writing achievements. For teachers, according to the errors, they can actively find means to help students make fewer such mistakes. For students, Error Analysis can help them find out which stage of language development they are in, so as to combine with teachers' suggestions to improve their English writing level. Through error analysis, the mistakes made by students can be divided into several types. According to the proportion of these error types, English teachers know the important and difficult points in English teaching so that a favorable basis for the adjustment of their own teaching methods are provided.

\section{LITERATURE REVIEW}

The critical mission of this part is to have a brief induction towards the (AES) Automatic Scoring System--Ju Ku. What's more, relative information about errors are also classified in this section. 
an important role in students' English writing. However, because of the limited English vocabulary of junior high school students, they cannot express their ideas fluently. As a result, some unsuitable English words have become their rigid choice. In view of the solutions to this difficult problem, $\mathrm{Ju} \mathrm{Ku}$ net contains relevant vocabulary discrimination and relevant examples to provide for students to acquire. Secondly, there are grammatical mistakes. For junior high school students, grammatical errors are not uncommon in their English compositions. Some learners will be confused in subject-predicate consistency and the confusion of tenses in the whole article. Aiming at the wrong application of grammar rules and Chinglish expressions, the $\mathrm{Ju} \mathrm{Ku}$ automatic correction network can give targeted amendments. providing feedback, AES mainly points out lexical and grammatical problems in their writing (Liao, 2016). As the basic unit of second language acquisition, vocabulary plays
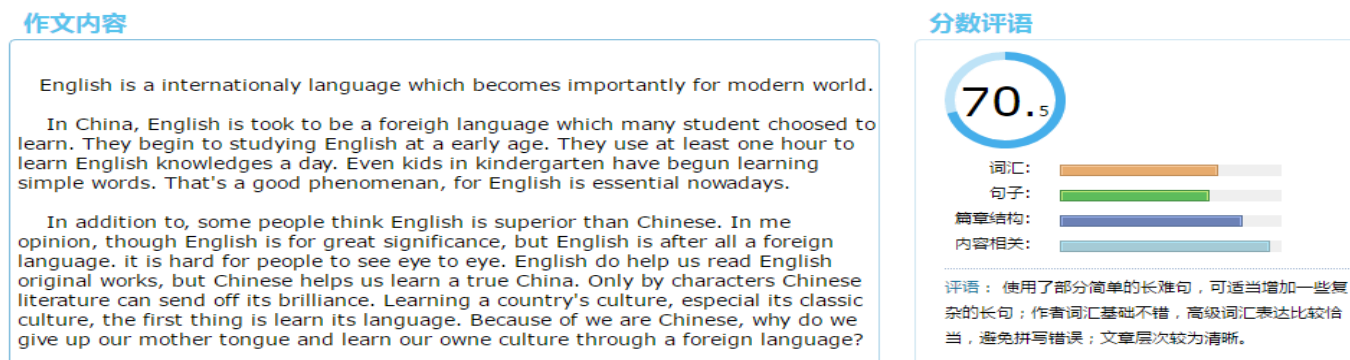

Figure 1 Example one

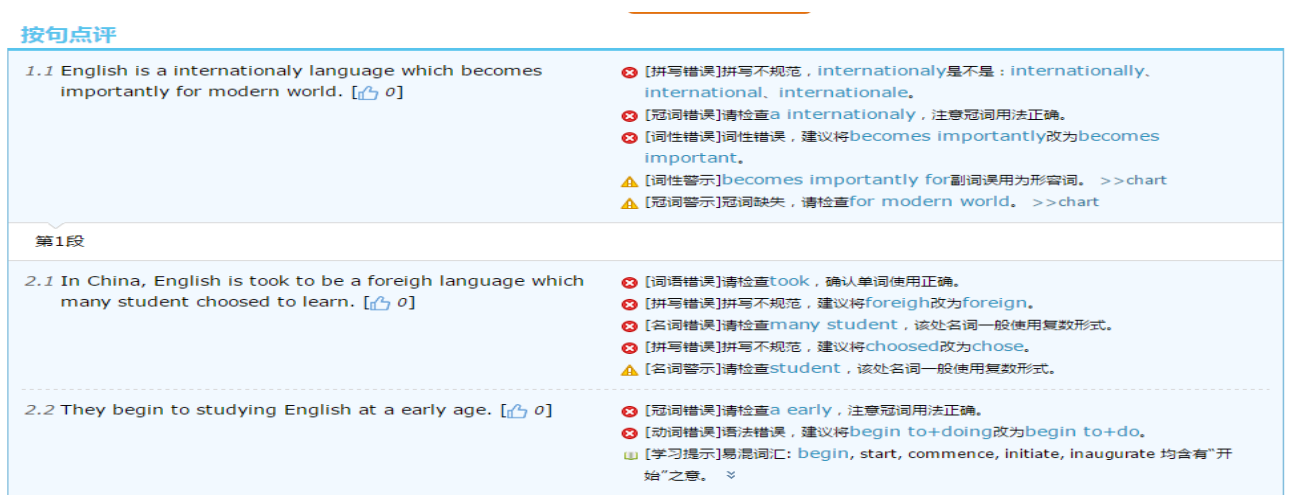

Figure 2 Example two

\subsection{Distinction of Mistakes and Errors}

Language mistakes and language errors are two different phenomena in language learning (Brown, 2000). "A mistake refers to a performance error that is either a random guess or a 'slip of tongue', and it's a failure performance to a known system" (pp. 218-219). A mistake is made because of a temporary breakdown, so it is easy for students to correct by themselves. An error, on the other hand, has something to do with the students' language performance. Errors do not result from carelessness nor hesitation, but lack of knowledge in the target language. Language errors cannot be corrected by students themselves even enough attention is given to them.

\subsection{The Theory of Error Analysis}

Being developed as a language learning method in the 1960s, EA mainly studied how learners learn a language. EA extends the study of errors on the basis of Contrastive Analysis Theory. American linguist Corder (1981) considers the research subjects in EA should be learner language rather than learners' native language and target language. And he also calls learner language idiosyncratic dialect. Nemser (1971) refers to approximative systems. These terms reflects two related but different concepts. Interlanguage refers to the structured system which the learner constructs at any given stage (in his development). Therefore, the substance of EA is a process of building a sound knowledge through finding the reasons why students made those errors.

\subsection{The Clarifications of $E A$}

According to different understanding towards errors, researchers have adopted different research methods for error classification, so the results are also very different. Many linguists have tried to classify errors in different ways, but many of them still have a lot of intersection. 
EA is based on cognitive psychology and generative linguistics. One of its basic assumptions is that there is a special mechanism in the human brain to deal with language knowledge. The purpose of this paper is to find out causes by analyzing and evaluating the errors in second language acquisition, so as to prevent or reduce the process of language errors. Because Error analysis shows the current English learning level of students intuitively.

\subsubsection{The Classification of Dulay \& Krashen}

In light of the degree whose errors influence the language communicative affect, they divide errors into two types. They are global and local errors respectively. Those errors that affect the main components of the whole sentence structure and ultimately lead to the fact that the whole sentence is difficult to understand or cannot understand are called global errors, for which teachers should correct them in a timely manner. If the result is not corrected, the communication cannot be carried out, that is, communicative function of the language will be lost. Local errors refer to errors that only affect a single element in a sentence, but what is said or written is basically understandable. For such errors, there is no need for teachers to correct. It may dispel the enthusiasm of students to learn. In addition, they also divide the errors into lexical errors, syntactic errors, grammatical morphological errors and sentence or discourse structure errors These errors are mainly caused by differences from correct lexical, syntactic, grammatical or discourse structure rules with the correct language rules.

\subsubsection{The Classification of Gao Yuan}

各类型错误出现次数

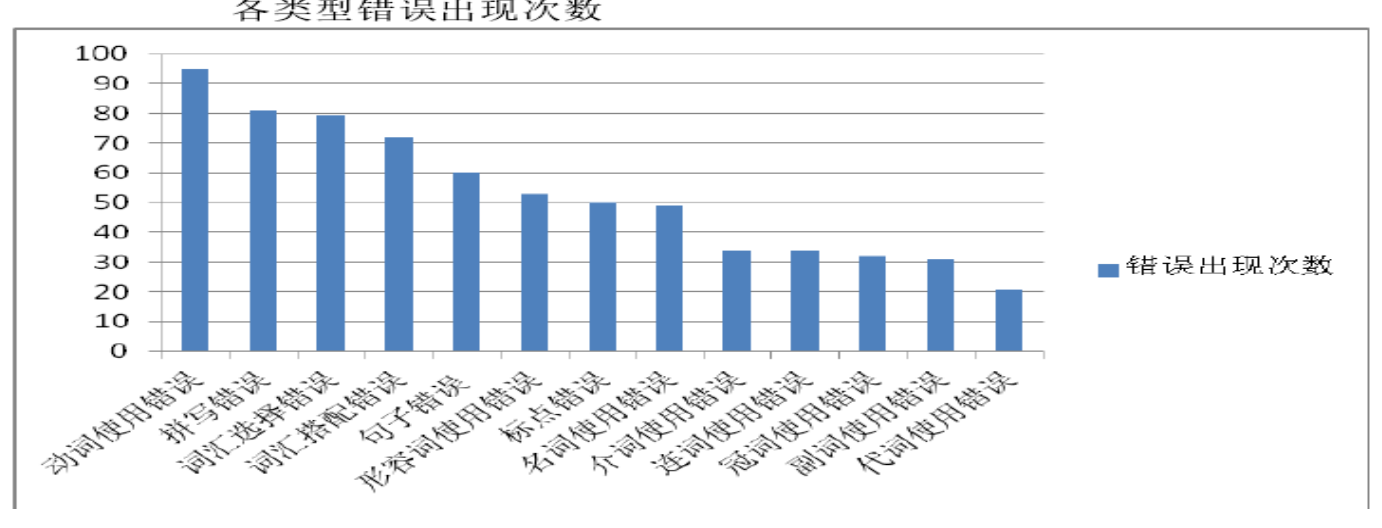

Figure 3 Example three

In addition, in the picture above, we can find that in English writing, students make the most mistakes in grammatical errors. In the huge English vocabulary database, verbs account for a large proportion of the proportion, it changes a lot, students have difficulties in mastering the use of verbs, resulting in a higher frequency of errors.
Gao (2002) put forward that errors can be divided into two types: interlingual errors and intralingual errors. Interlingual error is mainly affected by the negative transfer of students' native language. However, intralingual errors are caused when the learners do not have a comprehensive grasp of the rules of the target language and do not have a good understanding of the background knowledge of the target language. On the basis of Gao (2002), Zhou (2008) put forward interlingual errors, which are difficult to say whether they are interlingual errors or interlingual errors. This kind of error is analyzed from both lexical and syntactic aspects. Among the above categories, this paper focuses on the last two categories, namely, global error and local error.

\section{THE TYPES OF ERRORS AND PROPORTION IN STUDENTS' ENGLISH WRITING ON THE PLATFORM OF JU KU NET}

Through the analysis of the English writing texts of students in a junior middle school on the platform of Ju Ku net, it can be found out that there are mainly three types of mistakes that students make in a high frequency in English writing:

(1) lexical errors include vocabulary selection errors, lexical collocation errors and lexical spelling errors;

(2) grammatical errors include verb errors, noun errors, adjectives, adverbs, pronouns, articles and prepositions.

(3) discourse errors include conjunction errors and punctuation errors.

It is shown that English writing is an all-round investigation of students' English knowledge. In order to improve their English writing level, junior high school students need to have the accumulation of English knowledge.

\section{AN ANALYSIS OF THE MISTAKES IN STUDENTS' ENGLISH WRITING}

In this section, its task is to analyze the mistakes existing in students' English writing. The whole analysis mainly includes the following three aspects: grammatical, vocabulary and discourse errors. 


\subsection{Vocabulary Errors}

In the above-mentioned research, we have found that students make mistakes in the use of words. This type of error is mainly from the following three aspects: the word selection error, the vocabulary collocation error and the spelling error. It can be seen that it is a global mistake and the choice of different words will affect the reader's understanding of the whole sentence meaning. In that expression of Chinese, we often use the same word to express a variety of meaning. In contrast to Chinese, however, the expression of English requires that we make a choice of different words based on the environment in which we are located. There are many English words that are different in meaning, but in a specific context the meaning of their expression is different. This type of error in the writing of a student's English is because they don't have a sense of a similar term, leading to an error. For the error of the collocation type of the words, it is thought that it is a local error and does not affect the normal understanding of the sentence. The reason for this kind of errors are thought that students simply focus on the mastery of a single word in the course of learning English, leading to the neglect of the fixed collocation. The collocation of words in English is not fixed, and the collocation between them is very flexible, and the methods students applied to memorize the phrases are not conducive to the mastery of the students' English knowledge at all. An error in the spelling of words is a result of a local error that does not obscure the whole sentence. This type of error requires the student to be more careful in writing.

\subsection{Grammar Errors}

The grammatical errors analyzed here are global errors because this type of errors affect the expression of the meaning of the whole sentences. Students make this type of mistake because they are affected by their native Chinese language. In the first place, there are great differences between English and Chinese in the use of verbs. In Chinese language, the verbs used by learners do not change with the subject they choose to express, but this usage is completely different in English. Learners need to change the verb forms according to the subject of the main sentences. Secondly, there are differences in the structures used in expressing meaning between English and Chinese. The structure of English sentences is more rigorous and fixed than that of Chinese sentences. In English, individual adjectives, nouns, segmented words or numerals must be placed before the central word, phrases and clauses need to be placed at the end of the sentence, and adverbials are generally placed at the end of the sentence. Moreover, the word order of English interrogative sentence is different from that of declarative sentence. In interrogative sentence, the predicate should be at the beginning of sentence, or the auxiliary verb should be put at the beginning of sentence. Unlike English, attributives in Chinese need to be placed before the central language, and adverbials are generally placed between the subject and the predicate. The word order of interrogative sentences in Chinese does not change, but the question mark is added at the end of the sentence.

\subsection{Discourse Structure Errors}

In discourse errors, students will miss conjunctions and misuse punctuation marks. The reason for these two situations is that students do not have a clear grasp of the basic structure of sentences in English expression. In English, two complete sentences cannot be connected without conjunctions. However, this rule is often ignored by students. The main cause of misusing punctuation marks is that students do not understand the relationship between the sentences they write or do not understand the role of punctuation marks in sentences.

\subsection{Suggestions for Teachers to Reduce Students' Errors}

Error Analysis can not only help teachers and students find many problems in learning, but also help reduce the gap between the existing interlanguage level of middle school students and the target language. Besides that, teachers can develop more effective learning plans and teaching strategies according to the errors students made.

(1) Developing students' ability to memorize vocabulary

The importance of vocabulary to language learning is self-evident, but blindly reciting a single word and neglecting the collocation of words is of no help to the improvement of language output skills. The explanation of root, affix, connotation, collocation, word form and part of speech change rules is far more important than the single word itself, and firmly prevents students from blindly memorizing the Chinese meaning of the word. In addition, teachers should encourage students to become more exposed to extracurricular reading materials and original English books, and expand their knowledge reserves in reading.

(2) Explaining some important English grammar

For the important and difficult sentence patterns in the text and the fallible error structure of the students, the teacher should repeat those grammar points and let the students practice and practice again and again. Imitating or rewriting sentences is one of the ways for students to master knowledge points quickly. Only by combining theory with practice can students further deepen their memory and translate external knowledge into their own technical abilities.

(3) Extending input by all kinds of methods

Only enough language input can ensure good output, which requires teachers to strengthen the input of English language materials and information from many angles in daily teaching, and to create a mother tongue environment for students as far as possible. Playing the original recording, allowing students to read the original foreign works and so on cannot only enhance the sense of English language, but also make students familiar with the western mode of thinking and consciously carry out the conversion of writing thinking.

\section{CONCLUSION}

Based on the analysis of the errors pointed out in students' English writing by the automatic scoring system of related words, this paper finds that there are three types of errors 
made by junior middle school students in English writing. They are lexical errors, grammatical errors and discourse structure errors respectively. Through a series of analyses, we find out the reasons why students often commit this type: the transfer of learners' mother tongue and the lack of clarity about the structure of English sentences. Through this kind of permission, it can provide positive and beneficial practical significance for English writing teaching. In the teaching of English writing in the future, teachers should guide students to understand that English and Chinese are two different languages, and there are differences between them so that students can minimize the influence of negative transfer of their mother tongue on students' English writing. In addition, teachers should not only pay attention to students' memory of English vocabulary, but also put these words in the specific context of the article, so that students can realize their different usages. Secondly, teachers should also talk to students about the importance of discourse cohesion to English writing so that they can understand the relationship between sentences and finally the cohesion between sentences is logical.

\section{REFERENCES}

[1] Brown, H. D. (2000). Principles of Language Learni ng and Teaching (4th edition). London: Longman..

[2] Chukharew-Dianainen, E., \& Saricaoglu, A. (2016). Casual discourse analyzer: improving automated feedbac $\mathrm{k}$ on academic ESL writing. Computer Assisted Langua ge Learning. 29(3), 494.

[3] Dulay, H. Burt, M. and Krashen, S. (1982). Langua ge Two. New York: Oxford University Press.

[4] Gao, Y. (2002). Comparative Analysis and Error An alysis. Beijing: Beijing University of Aeronautics and A stronautics Press. (高远. 《对比分析与错误分析》 [M]. 北 京:北京航空航天大学出版社,2002.)

[5] Liao, H. C. (2016). Using automated writing evaluat ion to reduce grammar errors in writing. Academic, 70 (3): 308-319.

[6] Nemser, W. (1971). 'Approximative systems of forei gn language learners.' International Review of Applied L inguistics IX: 115-23.

[7] Pellegrino, J. W., \& Hilton, M. L. (Eds.). (2013). E ducation for life and work: Developing transferable kno wledge and skills in the 21 st century. Washington, DC: National Academies Press.

[8] Yang, S. L. (2016). An Analysis of the feedback fu nction of the automatic scoring system for English Writi ng. Specialty Construction and Education and Teaching Reform, 5(7): 25-28. (杨淑玲 (2016). 英语写作自动评分系 统反馈功能评析 $[\mathrm{J}]$. 专业建设与教育教学改革, 5(7): 25-2 8.)

[9] Yin, X. J., Jia, Y. H., \& Lin, Q. Y. (2017). An Em pirical Study on the Validity of the Automatic Score Va lidity of the Cool-net and Ice-Fruit. Journal of Hebei $N$ orth University，33(1):91-95.(殷小娟,贾永华,林庆英(201 7). “句酷网”和“冰果”自动评分效度的对比实证研究 [J]. 河北北方学院学报,33(1):91-95.)

[10] Zhou, Q. J. (2008). Case analysis of negative trans fer of mother tongue. Courses. Teaching materials. Teac hing methods, 20(5):11-13. (周启加,2008, 母语负迁移实 